\title{
EXPANSÃO RÁPIDA DE MAXILA CIRURGICAMENTE ASSISTIDA: RELATO DE CASO
}

Cicero BEZERUSKA, Delson COSTA, Nelson REBELATTO, Leandro KLUPPEL, Paulo Roberto MULLER

Para uma oclusão normal existe a necessidade de que o arco dentário superior guarde dimensões compativelmente maiores que as do arco dentário inferior. Quando estas dimensões forem menores no sentido lateral teremos uma deficiência transversal maxilar (CAPELOZZA 1997). Tentar corrigir uma deficiência óssea, na dimensão transversal, movimentando dentes, invariavelmente ocorrerá em recidivas (ARAUJO 1999). A expansão rápida da maxila é utilizada com previsibilidade em crianças e adolescentes, já em pacientes adultos este procedimento apresenta deficiências que podem levar 0 tratamento a um insucesso ou complicações (ALPERN 1987). Quando existir uma deficiência transversal maior que $5 \mathrm{~mm}$ em pacientes fora da fase de crescimento, em pacientes que já adquiriram maturidade esquelética, na existência de problemas periodontais, presença de uma mandíbula larga e em pacientes com idade esquelética de 15 anos ou mais a expansão rápida de maxila cirurgicamente assistida esta indicada (RIBEIRO 2006). Com este trabalho tivemos o objetivo de avaliar através de uma técnica de expansão rápida de maxila cirurgicamente assistida a quantidade de expansão maxilar conseguida, a qualidade desta expansão maxilar, morbidades relacionadas a este procedimento, assim como alterações estéticas e funcionais proporcionadas pelo auxílio cirúrgico à expansão maxilar.

Palavras-chave: expansão; maxila; atresia. 